\title{
The Effect of Successful Intelligence Training Program on Academic Motivation and Academic Engagement Female High School Students
}

\author{
Adeleh Sharbaf Zadeh ${ }^{1}$, Ahmad Abedi ${ }^{2}$, Zahra Yousefi ${ }^{3}$ \& Sara Aghababaei ${ }^{2}$ \\ ${ }^{1}$ Islamic Azad University, Oloom Tahghighat Branch, Isfahan, Iran \\ ${ }^{2}$ Department of children with special needs, University of Isfahan, Isfahan, Iran \\ ${ }^{3}$ Islamic Azad University, Oloom Tahghighat Branch, Isfahan, Iran \\ Correspondence: Sara Aghababaei, Department of children with special needs, University of Isfahan, Isfahan, \\ Iran. E-mail: Sara.aghababaei@ymail.com
}

Received: April 11, 2014

doi:10.5539/ijps.v6n3p118
Accepted: June 20, $2014 \quad$ Online Published: August 27, 2014

URL: http://dx.doi.org/10.5539/ijps.v6n3p118

\begin{abstract}
The purpose of this study is to investigate the effectiveness of successful intelligence training program on academic motivation and academic engagement in female high school students of Isfahan city, Iran. The statistical population of this study consisted of all female high school students of Isfahan city, Iran. Subjects were selected by multistep random cluster sampling. The successful intelligence training program was performed on the experimental group. Research instruments included Academic Engagement Questionnaire Archambault et al. (2009) and Academic Motivation Scale Vallerand et al. (1990). The variance analysis with repeated measures was used for data analysis. The results showed a significant difference between academic engagement scores of experimental and control group, in post-test and follow-up stages. This means that successful intelligence training was effective in increasing the academic motivation and academic engagement of female students. The results also indicated that the effect of training had been permanent in a long-term period. Therefore, according to the results, it would be possible to use successful intelligence training program in schools, besides other programs, in order to promote the academic motivation and engagement of students.
\end{abstract}

Keywords: successful intelligence training program, academic engagement, academic motivation

\section{Introduction}

\subsection{Academic Motivation}

Academic motivation constituent, in educational environments, refers to behaviors related to learning and improvement (Pintrich, 2004). Deci and Ryan (2002), define academic motivation as tendency of the learner to be involved in learning process and continuous effort to finish it. All motivational theories have accepted that there is a positive relationship between learners' academic motivation and academic performance. For example, Gottfried (1990), Burnett and Miller (1990), Pintrich and De Groot (1990), Deci et al (1991), Vallerand and Bissonnette (1992), Deci and Ryan (2000), Marsh and Hau (2004), Cokley and Patel (2007), Areepattamannil and Freeman (2008), have all mentioned the strong relationship between academic motivation and achievement. In this regard, several research evidences, also indicate that personal factors such as academic self-efficacy, academic self-concept, self-esteem, and perceived competence (Abedi, 2002), family factors such as expecting success from children, parental control, and authoritative parenting style (Abedi, 2004), and school factors such as teachers' enthusiasm and class circumstances (Kavousian \& Kadivar, 2004) all have a positive, significant relationship with academic performance.

\subsection{Academic Engagement}

Academic engagement refers to the quality of an attempt which students spend for purposeful learning activities, so that they could directly contribute to the achievement of desired results (Richardson, Long, \& Woodly, 2003). Academic engagement is a multi-dimensional constituent which is made of different behavioral, cognitive and motivational components (Archambault, Janosz, Fallu, \& Pagani, 2009; Martin, 2008; Martin \& Liem, 2010). According to Linnenbrink and Pintrich (2003), academic engagement consists of three dimensions of cognitive, motivational and behavioral: 
A) Cognitive academic engagement: includes a variety of cognitive and meta-cognitive strategies which are applied for learning, by students.

B) Motivational academic engagement (emotional): includes three components of feeling, values and affection. For example, this component reflects students' beliefs about why the courses and skills that they learn are useful, important and attractive.

C) Behavioral academic engagement: includes objective behaviors of students in dealing with their home works and also includes components of quest, stability and seeking help from others.

Studies have shown that there are a positive relationship between academic engagement and academic performance (Archambault et al., 2009; Fredericks, Blumenfeld, \& Paris, 2004; Furrer \& Skinner, 2003; Linnenbrink \& Pintrich, 2003; Martin, 2003; Martin, 2004; Martin, 2008; Martin \& Liem, 2010; Pintrich, 2000; Pintrich, 2003; Reschly \& Christenson, 2006; Richardson et al, 2003; Wolters \& Rosental, 2000).

Most of researches, about academic engagement, were correlational ones, and few studies have investigated the effectiveness of educational and psychological interventions on the increase of students' academic engagement (Martin, 2008). Also, most of these researches have studied the students' academic engagement with a single dimension, such as teachers' methodology and type of teaching and students' relationships with their teachers (Kelly \& Hansen, 1987), parental behavior and expectation from children (Dandy \& Nettlebeck, 2000), classmates (Wigfield \& Tonks, 2002), class circumstances (Qin, Johnson, \& Johnson, 1995), structure and culture of the school (Anderman \& Maehr, 1994), and social situation (Becker \& Luthar, 2002).

\subsection{Intelligence}

Serpell (2000) stated that what do people believe intelligence to be? In 1921, when the editors of the Journal of Educational Psychology asked 14 famous psychologists that question, the responses varied but generally embraced two themes: Intelligence involves the capacity to learn from experience and the ability to adapt to the surrounding environment. Sixty-five years later, Sternberg and Detterman (1986) asked 24 cognitive psychologists with expertise in intelligence research the same question. They, too, underscored the importance of learning from experience and adapting to the environment. They also broadened the definition to emphasize the importance of metacognition-people's understanding and control of their own thinking processes. Contemporary experts also more heavily emphasized the role of culture, pointing out that what is considered intelligent in one culture may be considered stupid in another (Sternberg, Jarvin, \& Grigorenko, 2011).

In recent years, the concept of intelligence is not considered as only a cognitive variable; and psychologists perceive intelligence in variety of ways. Early psychologists considered it as the ability of problem-solving. While others perceived it to be the ability to adapt and learn based on everyday experiences (Santrock, 2003). Furthermore, successful intelligence is a term introduced by Sternberg (1998), and it is one of the most important factors affecting academic motivation and engagement. Successful intelligence is a set of integrated capabilities which is necessary for obtaining success in life, and is nevertheless determined by the individual in his socio-cultural context. People who recognize their strengths and simultaneously their weaknesses and respectively use them more and find ways to compensate for or correct them, are successfully intelligent. Such people become adapted to the environment; also they shape it and choose it, all by making a balanced use of analytical, creative and practical capabilities (Sternberg \& Grigorenko, 2007).

Human intelligence is highly malleable and can be shaped and even increased through various kinds of interventions (Sternberg et al., 1997; Sternberg, Ferrari, Clinkenburd, \& Grigorenko, 1996). Zigler and Berman (1983) reported that, the Head Start program was initiated in the 1960s to provide preschoolers with an edge on intellectual abilities and accomplishments when they started school. Long-term follow-ups have indicated that by mid adolescence, children who participated in the program were more than a grade ahead of matched controls who did not experience the program (Sternberg, Jarvin, \& Grigorenko, 2011). The children in the program also scored higher on a variety of tests of scholastic achievement, were less likely to need remedial attention, and were less likely to show behavioral problems. Although such measures are not truly measures of intelligence, they show strong positive correlations with intelligence tests. Altogether, there is now abundant evidence that people's environments (e.g., Sternberg \& Wagner 1994), their motivation (e.g., Sternberg \& Ruzgis, 1994), and their training (e.g., Sternberg, 1987) can profoundly affect their intellectual skills. Thus, the controversial claims made by Herrnstein and Murray (1994) in their book, The Bell Curve, regarding the futility of intervention programs, are unfounded when one considers the evidence in favor of the possibility of improving cognitive skills (Sternberg, Jarvin, \& Grigorenko, 2011). 
In a set of studies Sternberg et al (1996); Sternberg, Grigorenko, Ferrari and Clinkenburd (1999), have shown that successful intelligence training affects students' academic performance, motivation and engagement.

According to Sternberg \& Grigorenko (2007) refers to role of culture as a significant factor in human intelligence and many studies demonstrates effectiveness of successful intelligence training program, therefore, the purpose of this study is investigating the effectiveness of successful intelligence training program on academic motivation and academic engagement of female high school students in Iran, Isfahan city.

\section{Method}

\subsection{Statistical Population}

The statistical population of this study consisted of all female high school students of Isfahan city, Iran.

\subsection{Samples}

The sample of this study included 30 female high school students. Multi-steps clustering sampling was used. In this way out of 6 educational areas of Isfahan city 2 areas were randomly selected. Then in 2 of these areas, 10 schools were randomly selected. Of all 10 schools 30 female students were randomly selected ( 3 students from each school). These students were randomly assigned into two groups (15 students in experimental group and 15 students in control group). 15 students in experimental group were gathered in a regular room in one of schools.

Entrance criteria included:

1) Complete satisfaction and willingness to participate in the training course.

2) Having general mental health

3) Complete satisfaction of parents for the participation of their children in the training program.

It is obvious that, students could not participate in the training program unless they had all the above conditions.

\subsection{Instruments}

\subsubsection{Questionnaire of Archambault et al. (2009)}

This questionnaire was made by Archambault et al. (2009). It contains 18 questions which evaluate three dimensions of academic engagement including: cognitive academic engagement (applying cognitive and meta-cognitive strategies in learning), motivational and emotional engagement (being interested in the school and the activities), and behavioral academic engagement (active presence at school besides enthusiasm). This questionnaire's materials are of the closed-reply test types with five options, which are scored by Likert scale of five points (5. Completely agree, 1. Completely disagree). Archambault et al. (2009) confirmed the validity of this questionnaire by factor analysis. As they have reported, the reliability coefficients (Cronbach's alpha) of cognitive academic engagement, motivational academic engagement and behavioral academic engagement were $0.88,0.83$ and 0.69 , respectively. The constituent validity of this questionnaire (its convergence with Pintrich's questionnaire) was obtained $0.78,0.79$ and 0.84 for behavioral academic engagement, emotional academic engagement and cognitive academic engagement, respectively.

\subsubsection{Academic Motivation Scale (AMS)}

This questionnaire was designed by Vallerand et al. (1990), and it is consisted of 28 questions. Academic motivation scale evaluates three constituents of motivation (including of interior motivation, exterior motivation and lack of motivation). The materials of this questionnaire are of closed-reply test types, having seven options, which are scored based on a Likert scale of seven points (7: Completely agree, 1: Completely disagree). The reliability coefficient (Cronbach's alpha) is reported by the internal consistency method to be $0.78,0.73$ and 0.92 for interior motivation, exterior motivation and the score of motivation in general, respectively. The reliability coefficient (Cronbach's alpha) of this questionnaire in the present study was obtained 0.80, 0.82 and 0.90 for interior motivation, exterior motivation and the score of motivation in general, respectively (Vallerand et al., 1993).

\subsection{Research Method}

The research method was experimental, with pretest and post-test and follow-up design. So here, successful intelligence training program (Sternberg \& Grigorenko, 2007), is the independent variable while academic engagement and academic motivation are dependent variables.

The questionnaire of Archambault et al (2009) and Academic Motivation Scale were performed on the students. After that, 30 students were randomly divided into two groups of experimental and control (15 students in experimental group and 15 students in control group). Successful intelligence training program (Sternberg \& 
Grigorenko, 2007) was performed in one of the schools for twelve sessions in experimental group (90 minutes per week). At the end of the sessions a post-test was given and two months later, after the end of sessions the follow-up test was given. Finally, the data was analyzed and findings were concluded.

\subsubsection{Training Sessions}

Teaching analytically means encouraging students to (a) analyze, (b) critique, (c) judge, (d) compare and contrast, (e) evaluate, and (f) assess. Teaching creatively means encouraging students to (a) create, (b) invent, (c) discover, (d) imagine if ..., (e) suppose that ..., (f) predict. Teaching for creativity requires teachers not only to support and encourage creativity but also to role-model it and to reward it when it is displayed (Sternberg \& Lubart, 1995; Sternberg \& Williams, 1996). In other words, teachers need not only to talk the talk, but also to walk the walk. Teaching practically mean encouraging students to (a) apply, (b) use, (c) put into practice, (d) implement, (e) employ, (f) render practical what they know. Such teaching must relate to the real practical needs of the students, not just to what would be practical for individuals other than the students (Sternberg et al., 2000).

Training sessions were designed based on Sternberg et al (2000) and Sternberg and Grigorenko (2007) and was conducted by trained professionals in the school.

Also, before the Successful intelligence training program, three experts agreed that the credibility of the program.

Table 1. Explanation of successful intelligence sessions

\begin{tabular}{ll}
\hline Session & Target Skills \\
\hline Session 1 & Introduction, welcoming, review of session structures and relevant laws. \\
& 1. Necessity and importance of successful intelligence training. \\
\hline Session 2 & $\begin{array}{l}\text { 1. Problem recognition: In this step, a problem solver both needs to recognize that a problem exists } \\
\text { and to determine what that problem is. 2. Resource specification: at this point, one who solves the } \\
\text { problem decides how much time, effort and other resources (such as money or staff) should be } \\
\text { specified to the problem solving process. 3. Presentation and organization of information: at this stage, } \\
\text { those who are engaged in problem solving need to present and organize the information } \\
\text { understandably and usefully. }\end{array}$ \\
\hline Session 3 3 & $\begin{array}{l}\text { 1. Strategy: the selection and presentation of information should be along with codifying a strategy in } \\
\text { order to initialize processes in the sequence that the problem solver would offer in presentation. } 2 .\end{array}$ \\
& $\begin{array}{l}\text { Monitoring strategies for problem solving: as problem solvers move on in the process of problem } \\
\text { solving, the should pursue whatever they have done up to that point, be aware of whatever they are } \\
\text { doing at that point and investigate whatever they have to do further. 3. Evaluation of solutions: this } \\
\text { stage involves a critical analysis of the solution to which a person has reached. Is the solution correct? } \\
\text { If there is no correct answer then, is it a good solution? }\end{array}$ \\
\hline Session 4 & $\begin{array}{l}\text { 1. Re-definition of the problem: defining a problem again means to consider a problem and change it } \\
\text { completely. }\end{array}$ \\
& $\begin{array}{l}\text { 2. Hypotheses investigation and analysis: every person makes a hypothesis. Often a person does not } \\
\text { know that he is making hypotheses because his hypotheses are largely in common. Creative people } \\
\text { make questions out of such hypotheses which finally lead to other questions made by other people. }\end{array}$ \\
Investigating hypotheses is part of analytical thinking involved in creativity. 3. Selling creative ideas: \\
people would like to imagine that their creative and fantastic ideas would certainly be counted perfect \\
and valuable.
\end{tabular}


these investments do not simply succeed. 2. Ambiguity tolerance: over time, a creative idea tends to become a part or component of something and also to develop. However, the period of time in which the idea is being developed seems unfavorable. Without the time and ability to tolerate ambiguity, people may adapt themselves to suboptimal solutions. 3. The increase of self-efficacy: sometimes people reach a point in their life where they think no one trusts or appreciates them and whatever they do. Since most of the times creative works are not warmly welcomed, it is so important for creative people to believe in the value of their work. 4. Discovering true interests: in order to set the best creative performances of students free, teachers could help them find whatever that motivates them, which might not be the same for everyone.

Session 7 1. Delay in success-making: Part of being creative is having the ability to work on a project or assignment for a long period of time without any immediate and temporary reward. Creative people must learn that rewards are not always immediate and that there are benefits in delaying success-making. 2. Modeling of creativity: there are many ways that the environment can foster creativity. Although this course is aimed at modeling teachers, students also can demonstrate and promote creativity for their classmates.

3. Being motivated: it is not of much importance that what talents do the students have, in case they have no motivation for applying them. Although not in most, in many environments, motivation, at least as same as mental skills, is important in achieving success.

4. Impulse control: there are times in life when people need to act impulsively; however, impulsive behavior tends to decrease the value of mental works, instead of increasing it.

Session 8 1. Having perseverance: in spite of their intelligence, some people surrender easily. If their work does not immediately result in what they wish or if their initial efforts for doing something are not successful, they would leave all of what they were doing.

2. Using the right abilities: during their life, many people may come up with the fact that they are having the wrong job or that they are involved in that job improperly. 3. Moving on according to the plan: some people are very adept in proposing solutions to their problems and it may seem that they have solutions for every problem in their life and in the life of other people as well; however, they are not capable of turning their thoughts into action. 4. Orientation to the production: some people are so concerned about the process on action; however, they almost do not care that much about the final outcome.

Session 9 1. Tasks accomplishment: the only certain prediction about those who do not accomplish works, is that whatever they begin they will not end. 2. Creating an obligation: it seems that some people do not want or are not able to begin a work or/and to be committed to it. Such people are always trying to decide what to do. 3. Risking: it seems that fear of failure begins from first years of one's life. Such a problem is so common, especially among those who have experienced many consecutive successes. 4 . Not postponing: it seems that putting things off is one of the realities of public life. All people postpone works at some special times. They put off the works that, as they know, must be done at the present time. When the only strategy to do things, for a person, is to put them off, it leads to a serious problem for him.

Session 10 1. Giving responsibility: some people think that they never do anything wrong and they are always looking for other people to blame them for even the smallest mistake ever. 2. Controlling self-sympathy: all people sometimes sympathize for themselves. It is difficult not to sympathize oneself when things are not going well enough. 3. Being independent: if a person wants to do something, it is best to either do it himself or accept the responsibility of asking someone else to do it.

Session 11 1. Inhibition of personal problems: everyone has personal problems but the amount of such problems varies from one person to another.

2. Concentration: there are many highly intelligent people who, in spite of their high intelligence, look unable to concentrate ever on something for a long period of time. 3. Proper planning: those who want to do many, simultaneously, sometimes would be unable to do anything. And that is not due to the fact that they did not try hard enough but because of the large number of projects they have made little progress. 
Session 12 1. Prioritizing: we all know some people, who are intellectually strong, but in the same way they are unsuccessful in their job, and that is because they are not able to see the generals rather than details.

2. Making balance between intellectual skills: people must sometimes be critical and analytical in their lives. And, at other times, they should have a creative and combined approach; moreover, there are times when they had better use a practical one. The important thing, though, is that people need to know when is the appropriate time for each approach.

3. Increasing self-confidence: in order to make a living, everyone needs to be more confident. There are a lot of traumas for people's self-esteem and also for their opinions about themselves, which cause them not to be safe from all of the obstacles, either small or big, that they face.

\section{Results}

The obtained data were evaluated through variance analysis with repeated measures, by SPSS18 software.

Hypothesis 1:

Successful intelligence training program is effective on increasing academic motivation of female high school students.

Table 2. Mean and standard deviation of test scores in academic motivation questionnaire (the total score) in pre-test, post-test and follow-up stages

\begin{tabular}{lllll}
\hline Variable & group & Stage & Mean & Standard deviation \\
\hline \multirow{3}{*}{ Academic motivation } & \multirow{3}{*}{ Experimental } & Pre-test & 101.03 & 10.21 \\
& & Post-test & 116.22 & 9.23 \\
\cline { 2 - 5 } & \multirow{3}{*}{ Control } & Follow-up & 118.33 & 8.67 \\
\hline & & Pre-test & 108.23 & 11.21 \\
& Post-test & 105.27 & 9.22 \\
& Follow-up & 104.14 & 9.32 \\
\hline
\end{tabular}

Table 2 shows mean and standard deviation of academic motivation test scores in pre-test, post-test and follow-up stages.

In order to investigate this hypothesis, the variance analysis with repeated measures was used.

Table 3. The results of the variance analysis with repeated measures of academic motivation scores

\begin{tabular}{lllllllll}
\hline sources & & $\begin{array}{l}\text { Sum of } \\
\text { squares }\end{array}$ & & $\begin{array}{l}\text { Mean } \\
\text { square }\end{array}$ & F & sig & Eta $^{2}$ & $\begin{array}{l}\text { observed } \\
\text { Power }\end{array}$ \\
\hline $\begin{array}{l}\text { Within- } \\
\text { subjects }\end{array}$ & factor & 883.08 & 2 & 441.54 & 12.61 & 0.001 & 0.31 & 0.99 \\
& $\begin{array}{l}\text { Factor and } \\
\text { group }\end{array}$ & 2337.22 & 2 & 1168.61 & 33.39 & 0.001 & 0.54 & 1 \\
\cline { 2 - 9 } $\begin{array}{l}\text { Between } \\
\text { subjects }\end{array}$ & error & 1959.69 & 56 & 34.99 & - & - & - & - \\
& group & 6333.61 & 1 & 6333.61 & 2.19 & 0.001 & 0.45 & 0.99 \\
& error & 7647.38 & 28 & 273.12 & - & - & - & - \\
\hline
\end{tabular}

As shown in table 3, the results of the variance analysis with repeated measures of academic motivation scores indicate a significant difference between the two groups of experimental and control $(p<0.05)$. Therefore, the first hypothesis, that is the effect of successful intelligence training program on increasing academic motivation of female high school students, is confirmed. The amount of training effect is $45 \%$ and the observed power shows that the volume of sample was adequate. 
Hypothesis 2:

Successful intelligence training program is effective on increasing academic engagement of female high school students.

Table 4. Mean and standard deviation of test scores in academic engagement questionnaire (the total score) in pre-test, post-test and follow-up stages

\begin{tabular}{lllll}
\hline Variable & group & Stage & Mean & Standard deviation \\
\hline \multirow{3}{*}{ Academic engagement } & \multirow{3}{*}{ Experimental } & Pre-test & 135.24 & 9.54 \\
& & Post-test & 147.61 & 7.74 \\
\cline { 2 - 5 } & & Follow-up & 149.29 & 9.65 \\
\cline { 2 - 5 } & \multirow{2}{*}{ Control } & Pre-test & 136.58 & 9.22 \\
& & Post-test & 136.80 & 8.32 \\
& & Follow-up & 137.29 & 8.01 \\
\hline
\end{tabular}

Table 4 shows mean and standard deviation of academic engagement test scores in pre-test, post-test and follow-up stages.

In order to investigate this hypothesis, the variance analysis with repeated measures was used.

Table 5. The results of the variance analysis with repeated measures of academic engagement scores

\begin{tabular}{|c|c|c|c|c|c|c|c|c|}
\hline sources & & $\begin{array}{l}\text { Sum of } \\
\text { squares }\end{array}$ & df & $\begin{array}{l}\text { Mean } \\
\text { square }\end{array}$ & $\mathbf{F}$ & sig & $\operatorname{Eta}^{2}$ & $\begin{array}{l}\text { observed } \\
\text { Power }\end{array}$ \\
\hline \multirow{3}{*}{$\begin{array}{l}\text { Within- } \\
\text { subjects }\end{array}$} & factor & 238.62 & 2 & 1191.81 & 18.6 & 0.001 & 0.43 & 1 \\
\hline & $\begin{array}{l}\text { Factor and } \\
\text { group }\end{array}$ & 181.02 & 2 & 906.01 & 1.14 & 0.001 & 0.33 & 0.99 \\
\hline & error & 358.02 & 56 & 64.09 & - & - & - & - \\
\hline \multirow{2}{*}{$\begin{array}{l}\text { Between } \\
\text { subjects }\end{array}$} & group & 402.71 & 1 & 4026.71 & 1.53 & 0.001 & 0.31 & 0.93 \\
\hline & error & 900.11 & 28 & 321.47 & - & - & - & - \\
\hline
\end{tabular}

As shown in table 5 , the results of the variance analysis with repeated measures of academic engagement scores indicate a significant difference between the two groups of experimental and control $(p<0.05)$. Therefore, the second hypothesis, that is the effect of successful intelligence training program on increasing academic engagement of female high school students, is confirmed. The amount of training effect is $31 \%$ and the observed power shows that the volume of sample was adequate.

\section{Discussion}

The findings of the present study showed that successful intelligence training program is effective on increasing academic motivation and engagement in female high school students. The findings of this study are consistent with the results of some other studies for examples: (Sternberg et al, 1996; Sternberg et al, 1999; Sternberg, Grigorenko, \& Zhang, 2008; Sternberg, Troff, \& Grigorenko, 1998).

Why should teaching for successful intelligence improve performance relative to standard (or critical-thinking) instruction? There are at least four reasons. First, teaching for successful intelligence encourages deeper and more elaborated encoding of material than does traditional teaching, so that students learn the material in a way that enhances probability of retrieval at time of test. Second, teaching for successful intelligence encourages more diverse forms of encoding material, so that there are more retrieval paths to the material and hence there is greater likelihood of recall at time of test. Third, teaching for successful intelligence enables students to capitalize on strengths and to correct or compensate for weaknesses. Fourth, teaching for successful intelligence is more motivating to both teachers and students, so that the teachers are likely to teach more effectively and the students are likely to learn more (Sternberg, Jarvin, \& Grigorenko, 2011). 
In explaining these results, it can be said that in successful intelligence training class in this research, the students conclude that there is a space beyond the so-called academic success. What actually is beyond academic success is success in life, which includes three components of analytical, creative and practical abilities. That means, if a student, who is studying at a school, uses the knowledge she/he is exposed to analytical intelligence creatively in an applicable and practical way in life, he/she could be considered as having success in life. It is concluded from successful intelligence training class that the students realized that by being exposed to an apt and appropriate learning environment, and also by uniqueness and diversity of the programs, all have been given the opportunity of showing who they are based on their learning patterns, and therefore they can improve their self-confidence. At this point, students feel that they are accepted and that they can, as well, understand, accept and respect other community members. The students also found out that they must be strong and resistant against failures and should find secondary and alternative ways in order to dominate difficult things.

In another explanation, it could be said that the students learned to solve the problems more efficiently in difficult situations, by redefining the problems. They realized that during an activity which is consistent with their abilities, they should invest on their positive ones and there of find their weak points, which are not consistent with their abilities, and compensate for or correct them. It seems that they have discovered their own learning pattern and through such a discovery, they have found their knowledge and consequently their uniqueness. They also realized that the existence of a supportive environment could be effective on their motivation and engagement toward learning. They perceived that having motivation in many situations is important in achieving success, at least as same as mental skills. They found out that resources of motivation are necessary for divulging one's intelligence abilities and succeeding.

Considering the fact that by increasing academic level, the role of creative and practical thinking also becomes more prominent in the explanation of academic achievement and improvement. It seems that, schools must give more importance to these two factors.

One of Limitations this research was that conducted on female students and would be suggested that on male students have be done. Another limitation can be Family, educational and personal factors that they have an impact on students' academic motivation and engagement of experimental group and control that had not received training. Also, another limitation is the small sample size; it is recommended that future studies be conducted with larger sample size.

\section{Acknowledgements}

We gratefully acknowledge the help of the students, teachers and school staff who participated in the study without whom this research would not possible.

\section{References}

Abedi, A. (2002). The relationship between academic achievement motivation of high school students with personality and family characteristics. Amooze Journal, 13, 14-25.

Abedi, A. (2004). Meta-analysis of factors affecting on motivation in high school students. Education Research Council of Isfahan.

Anderman, E. A., \& Maehr, M. L. (1994). Motivation and schooling in the middle grades. Review of Educational Research, 64, 287-310. http://dx.doi.org/10.3102/00346543064002287

Archambault, I., Janosz, M., Fallu, J., \& Pagani, L. (2009). Student engagement and its relationship with early high school dropout. Journal of adolescence, 32(3), 651-670. http://dx.doi.org/10.1016/j.adolescence.2008.06.007

Areepattamannil, S., \& Freeman, J. G. (2008). Academic achievement, academic self concept, and academic motivation of immigrant adolescents in the greater Toronto area secondary schools. Journal of Advanced Academics, 19, 700-743.

Becker, B. E., \& Luthar, S. S. (2002). Social-emotional factors affecting achievement outcomes among disadvantaged students: Closing the achievement gap. Educational Psychologist, 37, 197-214. http://dx.doi.org/10.1207/S15326985EP3704_1

Berndt, T. J., \& Miller, K. E. (1990). Expectancies, values, and achievement in junior high school. Journal of Educational Psychology, 82, 319-326. http://dx.doi.org/10.1037/0022-0663.82.2.319

Cokley, K., \& Patel, N. (2007). A psychometric investigation of the academic self-concept of Asian American college students. Educational and Psychological Measurement, 67, 88-99. http://dx.doi.org/10.1177/0013164406288175 
Dandy, J., \& Nettelbeck, T. (2000). The model student? An investigation of Chinese Australian students' academic achievement, studying, and causal attributions for academic success and failure. Australian Psychologist, 35, 208-215. http://dx.doi.org/10.1080/00050060008257480

Deci, E. L., \& Ryan, R. M. (2000). Self-determination theory and the facilitation of intrinsic motivation, social $\begin{array}{lllll}\text { development, and well being. American Psychologist, } & \text { 55, }\end{array}$ http://dx.doi.org/10.1037/0003-066X.55.1.68

Deci, E. L., \& Ryan, R. M. (2002). A motivational approach to the self: Integration in personality. In R. Dienstbier (Ed.), Nebraska Symposium on Motivation (vol. 38, pp. 237-288). Lincoln University of Nebraska Press.

Deci, E. L., Vallerand, R. J., Pelletier, L. G., \& Ryan, R. M. (1991). Motivation and education: The self-determination perspective. The Educational Psychologist, 26, 325-346. http://dx.doi.org/10.1080/00461520.1991.9653137

Fredericks, J. A., Blumenfeld, P. C., \& Paris, A. H. (2004). School engagement: Potential of the concept, state of the evidence. Review of Educational Research, 74, 59-109. http://dx.doi.org/10.3102/00346543074001059

Furrer, C., \& Skinner, E. (2003). Sense of relatedness as a factor in children's academic engagement and $\begin{array}{lllll}\text { performance. Journal of } & \text { Educational }\end{array}$ http://dx.doi.org/10.1037/0022-0663.95.1.148

Gottfried, A. E. (1990). Academic intrinsic motivation in elementary and junior high school students. Journal of Educational Psychology, 77, 631-645. http://dx.doi.org/10.1037/0022-0663.77.6.631

Herrnstein, R. J., \& Murray, C. (1994). The bell curve. New York: Free Press.

Kavousian, J., \& Kadivar, P. (2004). Investigating factors affecting on academic motivation of high school students. Tehran: Research Project of the Ministry of Education.

Kelly, J. A., \& Hansen, D. J. (1987). Social interactions and adjustment. In V. B. Can Hasselt, \& M. Hersen (Eds.), Handbook of adolescent psychology (pp. 131-146). Pergamon Press: Springer.

Linnenbrink, E. A., \& Pintrich, P. R. (2003). Motivation as an enabler for academic success. The School Psychology Review, 31, 313-327.

Linnenbrink. A., \& Pintrich. P. A (2003). The role of self-efficacy beliefs in student engagement and learning in the classroom. Reading \& Writing Quarterly: Overcoming Learning Difficulties, 19(2), 119-137.

Marsh, H. W., \& Hau, K. T. (2004). Explaining paradoxical relations between academic self-concepts and achievements: Cross-cultural generalizability of the internal/external frame of reference predictions across 26 countries. Journal of Educational Psychology, 96, 56-67. http://dx.doi.org/10.1037/0022-0663.96.1.56

Martin, A. J. (2003). Enhancing the educational outcomes of boys: Windings from the A.C.T investigation into boys' education. Youth Studies Australia, 22, 27-36.

Martin, A. J. (2004). School motivation of boys and girls: Differences of degree, differences of kind, or both? Australian Journal of Psychology, 56, 133-146. http://dx.doi.org/10.1080/00049530412331283363

Martin, A. J. (2008). Enhancing student motivation and engagement: The effect of a multidimensional $\begin{array}{llll}\text { intervention. } & \text { Contemporary 239-269. }\end{array}$ http://dx.doi.org/10.1016/j.cedpsych.2006.11.003

Martin, A. J., \& Liem, G. A. D. (2010). Academic personal bests (PBs), engagement, and achievement: A cross-lagged panel analysis. Learning and Individual Differences, 24, 265-270. http://dx.doi.org/10.1016/j.lindif.2010.01.001

Pintrich, P. R. (2000). Multiple goals, multiple pathways: The role of goal orientation in learning and $\begin{array}{lllll}\text { achievement. Journal of Educational } & \text { Psychology, }\end{array}$ http://dx.doi.org/10.1037/0022-0663.92.3.544

Pintrich, P. R. (2003). A motivational science perspective on the role of student motivation in learning and teaching contexts. Journal of Educational Psychology, 95, 667-686. http://dx.doi.org/10.1037/0022-0663.95.4.667

Pintrich, P. R. (2004). A motivational science perspective on the role of student motivation in learning and teaching contexts. Journal of Educational Psychology, 95, 667-686. http://dx.doi.org/10.1037/0022-0663.95.4.667 
Pintrich, P. R., \& DeGroot, E. V. (1990). Motivational and self-regulated learning components of classroom academic performance. In M. L. Maehr, \& P. R. Pintrich (Eds.), Advances in motivation and achievement, (vol. 7, pp. 371-401). Greenwich, CT7 JAI Press.

Qin, Z., Johnson, D. W., \& Johnson, R. T. (1995). Cooperative versus competitive efforts and problem solving. Review of Educational Research, 65, 129-144. http://dx.doi.org/10.3102/00346543065002129

Reschly, A., \& Christenson, S. L. (2006). School completion. In G. Bear, \& K. Minke (Eds.), Children's Needs-III: Development, Prevention, and Intervention. Washington DC National Association of School Psychologists.

Richardson, T. E., Long, G. L., \& Woodly, A. (2003). Academic engagement and perception of quality in distance education. Open Learning, 18, 23-38. http://dx.doi.org/10.1080/0268051032000131008

Santrock, J. W. (2003). Adolesence (9th ed.). Newyork: McGraw-Hill Company.

Serpell, R. (2000). Intelligence and culture. In R. J. Sternberg (Ed.), Handbook of intelligence (pp. 549-577). New York: Cambridge University Press. http://dx.doi.org/10.1017/CBO9780511807947.026

Sternberg, R. J. (1998). Abilities as forms of developing expertise. Educational Researcher, 27, 11-20. http://dx.doi.org/10.3102/0013189X027003011

Sternberg, R. J. (1987). Teaching intelligence: The application of cognitive psychology to the improvement of intellectual skills. In J. B. Baron, \& R. J. Sternberg (Eds.), Teaching thinking skills: Theory and practice (pp. 182-218). New York: Freeman.

Sternberg, R. J., \& Detterman, D. K. (Eds.). (1986). What is intelligence? Norwood, NJ: Ablex.

Sternberg, R. J., Forsythe, G. B., Hedlund, J., Horvath, J., Snook, S., Williams, W. M., Wagner, R. K., \& Grigorenko, E. L. (2000). Practical intelligence in everyday life. New York: Cambridge University Press.

Sternberg, R. J., \& Grigorenko, E. L. (2007). Teaching for successful intelligence (2nd ed.). Thousand Oaks, CA: Corwin Press.

Sternberg, R. J., Ferrari, M., Clinkenbeard, P. R., \& Grigorenko, E. L. (1996). Identification, instruction, and assessment of gifted children: A construct validation of triarchic model. Gifted Child Quarterly, 40, 129-137. http://dx.doi.org/10.1177/001698629604000303

Sternberg, R. J., Grigorenko, E. L., Ferrari, M., and Clinkenbeard, P. (1999). A triarchic analysis of an aptitude-treatment interaction. European Journal of Psychology Assessment, 15(1), 1-11. http://dx.doi.org/10.1027//1015-5759.15.1.3

Sternberg, R. J., Grigorenko, E. L., \& Zhang, L.-F. (2008). Styles of learning and thinking matter in instruction and assessment. Perspectives on Psychological Science, 3(6), 486-506. http://dx.doi.org/10.1111/j.1745-6924.2008.00095.x

Sternberg, R. J., Jarvin, L., \& Grigorenko, E. L. (2011). Explorations in Giftedness. Cambridge University Press.

Sternberg, R. J., \& Lubart, T. I. (1995). Defying the crowd: Cultivating creativity in a culture of conformity. New York: Free Press.

Sternberg, R. J., Powell, C., McGrane, P. A., \& McGregor, S. (1997). Effects of a parasitic infection on cognitive functioning. Journal of Experimental Psychology: Applied, 3, 67-76. http://dx.doi.org/10.1037/1076-898X.3.1.67

Sternberg, R. J., \& Ruzgis, P. (Eds.). (1994). Personality and intelligence. New York: Cambridge University Press.

Sternberg, R. J., Torff, B., \& Grigorenko, E. L. (1998). Teaching for successful intelligence raises school achievement. Phi Delta Kappan, 79, 667-669.

Sternberg, R. J., \& Wagner, R. K. (Eds.). (1994). Mind in context. New York: Cambridge University Press.

Sternberg, R. J., \& Williams, W. M. (1996). How to develop student creativity. Alexandria, VA: Association for Supervision and Curriculum Development.

Vallerad, R. J., \& Bissonnette, R. (1992). Intrinsic, extrinsic, and motivational styles as predictors of behavior: A $\begin{array}{lllll}\text { prospective study. Journal of } & \text { 5ersonality, } & 60, & \text { 59 }\end{array}$ http://dx.doi.org/10.1111/j.1467-6494.1992.tb00922.x 
Vallerand, R. J., Pelletier, L. G., Blais, M. R, Brière, N. M., Sené-cal, C., \& Vallières, E. F. (1993). On the assessment of intrinsic, extrinsic and motivation in education: Evidence on the concurrent and construct validity of the academic motivation scale. Educational and Psychological Measurement, 53, 159-172. http://dx.doi.org/10.1177/0013164493053001018

Wolters, C. A., \& Rosental, H. (2000). The relation between student motivational beliefs and their use of motivational regulation strategies. International Journal of Educational Research, 33, 801-820. http://dx.doi.org/10.1016/S0883-0355(00)00051-3

Wigfield, A., \& Tonks, S. (2002). Adolescents' expectancies for success and achievement task values during middle and high school years. In F. Pajares, \& T. Urdan (Eds.), Academic motivation of adolescents. Connecticut: Information Age Publishing.

Zigler, E., \& Berman, W. (1983). Discerning the future of early childhood intervention. American Psychologist, 38, 894-906. http://dx.doi.org/10.1037/0003-066X.38.8.894

\section{Copyrights}

Copyright for this article is retained by the author(s), with first publication rights granted to the journal.

This is an open-access article distributed under the terms and conditions of the Creative Commons Attribution license (http://creativecommons.org/licenses/by/3.0/). 